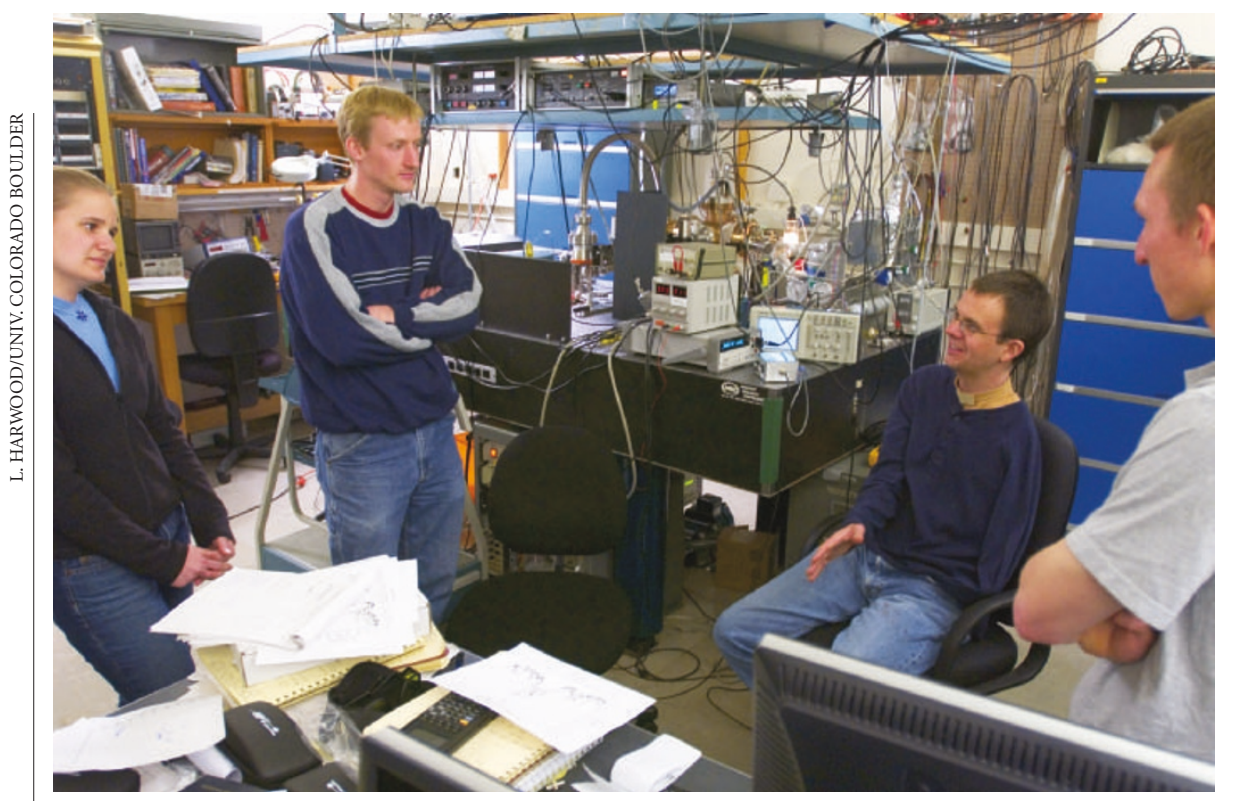

Much missed: Eric Cornell (sitting) is thrilled to start supervising his physics students again.

\title{
Nobel laureate triumphs over loss of arm and returns to lab
}

Kendall Powell, Boulder

Eric Cornell has experienced life's extremes. He won the physics Nobel prize in 2001, but last October he lost his left arm and shoulder — and nearly his life — to a fleshkilling bacterial infection. He has, however, bounced back and was in playful mood last week as he announced his return to the scientific fray.

"Losing an arm is more an inconvenience than a catastrophe," Cornell told a 12 April press conference organized by the University of Colorado at Boulder. "I should emphasize that I was right-handed before. And here it is." He waved at the assembled reporters.

Cornell will be fitted for a prosthetic arm, and hopes to have an attachment that will allow him to play pool. "The bets will go down, and then I'll put on the arm," he joked.

Doctors say Cornell is lucky to be alive after contracting necrotizing fasciitis, a rare and invasive streptococcal infection. Although he cannot recall injuring himself, the bacteria probably entered through a scratch or cut.

On 24 October 2004, he developed flulike symptoms. The next day he felt a pain in his shoulder that steadily worsened, and within three days he was in the emergency room. Doctors surgically removed his left arm and shoulder and placed skin grafts on his torso. In a medically induced coma until late November, Cornell returned home from the hospital in mid-December.

Still undergoing physical therapy for his skin grafts, Cornell has phantom sensations of the missing arm: he feels as if it's behind his back. And he is taking medication for phantom pain, a common problem for amputees.

Cornell has already returned part-time to his lab at JILA, the institute run jointly by the
University of Colorado and the National Institute of Standards and Technology where he and his colleague Carl Weiman created a new form of matter called a Bose-Einstein condensate. That achievement won the duo the 2001 Nobel Prize in Physics, which they shared with Massachusetts Institute of Technology researcher Wolfgang Ketterle.

"Before I got sick, I thought I had one of the best jobs in the world," Cornell said. Thrilled to be back, he has been adjusting to using voice-recognition software instead of typing, and he won't be operating lathes or lasers. But he will continue to supervise students, which was taking up most of his time before his illness anyway. "It has to be said that it's been a little while since I've done very many fine adjustments on a laser," he said. "I usually offer helpful advice to my students and I'm as much a motormouth as ever."

That advice was much missed by lab members during his absence, says Aaron Leanhardt, a postdoc who arrived at Cornell's lab the week after he went into the hospital. "It will certainly be nice to be able to walk into his office and have a spontaneous discussion," Leanhardt says.

Cornell is now embarking on several studies involving Bose-Einstein condensates, as well as searching for an elusive property of the electron known as its permanent dipole moment. Physicists usually think of electrons as tiny, negatively charged spheres, but the charge might be asymmetrically distributed across the particle. That makes electrons a bit like people, Cornell told reporters: "Not one of us is really symmetrical."

His wife, Celeste Landry, couldn't resist adding a punchline: "You're one to talk!" Additional reporting by Geoff Brumfiel.

\section{Ecologist sues for lost tenure following transgene quarrel}

Rex Dalton, San Diego

A Mexican ecologist renowned for his criticism of transgenic crops is suing the University of California, Berkeley, which denied him tenure in 2003.

Ignacio Chapela was prominent among staff at Berkeley who opposed a five-year, \$25-million deal that in 1998 gave the Swiss firm Novartis privileged access to findings by the university's plant scientists. The lawsuit claims that he was denied tenure in retaliation for this stance. Chapela also claims to be the victim of racial discrimination. "My case shows the tenure review process is totally overwhelmed by the forces of politics and the realities of economic dependency," he says.

Chapela rose to international attention with a 2001 paper reporting that transgenes had flowed into native varieties of maize in southern Mexico and fragmented throughout their genomes (D. Quist and I. H. Chapela Nature 414, 541-543; 2001). After the paper was criticized by plant biotechnologists and subjected to additional review, Nature issued a statement saying that it would not have been published had certain technical flaws been uncovered. But Chapela stands by the findings.

As these events were unfolding, Berkeley was considering Chapela's request for tenure in the College of Natural Resources. Although Chapela's department and the college voted in his favour, the university's chancellor at the time, Robert Berdahl, denied him tenure, saying his research record was insufficient. Since then, Chapela's case has become a focus for protesters concerned about threats to academic freedom from industrial forces.

Last year, a compromise was worked out in which university administrators agreed to convene a committee to reassess Chapela's tenure. This committee will make a recommendation to Berkeley's new chancellor, Robert Birgeneau, who was inaugurated on 15 April. He will rule on whether Chapela should receive tenure by 30 June - the end of the academic year.

Chapela says he is not optimistic about the review: "I see the academic process as unable to deal with the questions raised here." For now, he remains a salaried employee with an office and lab, but no funds for research.

The university declines to comment on the legal action. 